\title{
PRUSS, MOTIVATIONAL CENTRALITY, AND PROBABILITIES ATTACHED TO POSSIBILITY PREMISES IN MODAL ONTOLOGICAL ARGUMENTS
}

\author{
GRAHAM OPPY \\ Monash University
}

\begin{abstract}
Pruss (2010) argues that consideration of the motivational centrality of Theistic belief in flourishing and intellectually sophisticated lives of significant length provides reason for thinking that Theistic belief is at least possibly true. But Theistic belief is belief in a necessarily existent God. So, according to Pruss, consideration of the motivational centrality of Theistic belief in flourishing and intellectually sophisticated lives of significant length provides reason for thinking that there is a necessarily existent God. Pruss's gambit is the most interesting original move in the recent literature on modal ontological arguments and, on that account, deserves detailed analysis. In this paper, I aim to provide just such an analysis. Perhaps unsurprisingly, I argue for the conclusion that Pruss's gambit should be declined.
\end{abstract}

Pruss (2010) offers a novel defence of possibility premises in modal ontological arguments. In particular, he offers a new way of arguing that these possibility premises are 'probably true'. I propose to argue that Pruss's defence is unconvincing: in the end, it probably amounts to nothing more than an expression of prejudice against worldviews that reject that claim that God is essentially omnipotent, essentially omniscient, essentially perfectly good, essentially the creator of all else, and necessarily existent.

\section{MODAL ONTOLOGICAL ARGUMENTS}

Suppose that we focus on a conception of God which holds that, if God exists in at least one possible world, then God exists in all possible worlds. 
Suppose further that we maintain that S5 is the correct modal logic that governs reasoning concerning God as thus conceived.

We can represent the range of considered rational opinion concerning this conception of God, on the further assumption about the relevant correct modal logic, in the following way: (1) Theism: $\{$ It is possible that God exists, God exists, It is necessary that God exists\}; (2) Atheism: \{It is possible that God does not exist, God does not exist, It is necessary that God does not exist\}; (3) Agnosticism: Suspension of belief between (1) and (2).

On the one hand, given the conception of God and the further assumption about the relevant correct modal logic, each of the claims attributed to Theism entails the other claims attributed to Theism; and, on the other hand, given the conception of God and the further assumption about the relevant correct modal logic, each of the claims attributed to Atheism entails the other claims attributed to Atheism. Given these first two observations, it is clear that considered, rational Agnosticism requires suspension of belief concerning each of the three pairs of claims attributed to Theism and Atheism; and, in particular, it is clear that considered, rational Agnosticism requires suspension of belief between the claim that it is possible that God exists and the claim that it is possible that God does not exist.

Given the entailments just noted, it is easy to see that the following two arguments are valid: (1) It is possible that God exists so God exists (and, indeed, it is necessary that God exists); (2) It is possible that God does not exist so God does not exist (and, indeed, it is necessary that God does not exist). However, given the symmetry of the advanced considerations, it is also easy to see that, on their own, these arguments do nothing to decide between Theism, Atheism and Agnosticism. On the one hand, rational Theists will suppose that the first argument is sound, and the second unsound; on the other hand, rational Atheists will suppose that the second argument is sound, and the first argument is unsound. And, of course, rational Agnostics will suspend judgement on the question which of the two arguments is sound.

Whether there are considerations that decide between Theism, Atheism and Agnosticism may depend upon what else is taken to be part of the conception of God at issue. If we suppose that, if God exists in at least one possible world, then God is perfectly good, omnipotent, omniscient, and creator of all else in every possible world, then there is a range of considerations that we can take into account in weighing 
the claim that God exists against the claim that God does not exist (or, equivalently, in weighing the claim that it is possible that God exists against the claim that it is possible that God does not exist). If we suppose that, if God exists in at least one possible world, then God is the one and only god - the one and only supernatural being or force that has and exercises power over natural reality that is not, in turn, under the power of higher-ranking or more powerful beings or forces - in every possible world, then there is a perhaps different range of considerations that we can take into account in weighing the claim that God exists against the claim that God does not exist. And so on, for other proposals about what else is part of the conception of God.

There is, I think, fairly strong prima facie reason to suppose that modal ontological arguments do not have a serious contribution to make to the decision between Theism, Atheism, and Agnosticism. In particular, if we allow that there are many considerations that bear on the question whether God exists - e.g. considerations about the origins of causal reality, the fine-tuning of natural reality, the quantity of horrendous evil in natural reality, the presence of consciousness and reason in causal reality, the insignificance of human beings on any cosmic scale, the apparent objectivity of various normative domains (e.g. the logical, the mathematical, the moral, the aesthetic, etc.), the range and distribution of religious belief, the nature and existence of diverse canonical religious texts, the range of attestations to the occurrence of 'anomalous' phenomena, the quantity and kinds of great goods to be found in natural reality, and so forth - then it seems that we should expect that the decision between Theism, Atheism, and Agnosticism will depend upon some careful weighing of these many considerations.

Even if we suppose that the decision between Theism, Atheism and Agnosticism will depend upon the careful weighing of a large range of considerations, we might still suppose that there is some interest that attaches to the evaluation of these positions with respect to particular considerations, all other considerations being ignored. Thus, for example, we might suppose that some interest attaches to the question whether Theism, Atheism, or Agnosticism is most favoured by the range and distribution of religious belief on the Earth at the beginning of the twenty-first century, all other considerations being ignored. However, there are at least two grounds for scepticism about this kind of supposition. On the one hand, it might be doubted that, even in principle, the decision between our positions on total evidence can be 
decomposed into a sum over decisions on particular pieces of evidence, all other evidence being then ignored. And, on the other hand, it might be doubted whether, in practice, decisions between our positions on total evidence do decompose into sums over decisions on particular pieces of evidence, all other evidence being then ignored. The above misgivings notwithstanding, we shall proceed on the assumption that at least academic interest attaches to questions that concern decisions between our positions on the basis of particular pieces of evidence, all other evidence being then ignored.

\section{UNIFORMLY SAMPLED BELIEF AND LIKELIHOOD OF TRUTH}

Suppose that we sample uniformly from the pool of human beliefs. (It doesn't matter whether we take a current sample, or a sample over some range of human history, or even a sample over the whole of human history.) What should we say about the likelihood that the belief that we select is true?

There are various considerations that might be taken to tell in favour of the claim that it is more likely than not that our chosen belief is true. Some might appeal to Davidsonian principles of interpretation; some might appeal to Wittgensteinian considerations about hinge propositions; some might appeal to evolutionary considerations about environmental fit; and so forth.

Suppose that, for whatever reasons, we should say that a uniformly sampled belief is more likely than not to be true. Then, it seems, we should also say that, if the only information that we have is that a given belief is held, then we should hold that it is more likely than not that the belief in question is true. (If asked to bet on whether a belief is true or not, given only the information that the belief in question is held, we should bet that the belief is true.)

Here's an easy application of our assumptions to this point: if we are given the information that the belief that God does not exist is held, then, in the absence of any further information, it is more likely than not that God does not exist. That is, we should judge that, setting all other information aside, the information that the belief that God does not exist is held licenses the claim that it is more likely than not that God does not exist. Said differently: if we set aside all other information, except the information that the belief that God does not exists is held, 
then the information that we have favours Atheism over either Theism or Agnosticism.

It is not easy to get excited about this. After all, in the context of debate about Atheism, Theism, and Agnosticism, it is common ground that each position is held. Moreover, it is common ground that no rational person can occupy more than one of these positions (at a single time). If we set aside all other information, except the information that the belief that God exists is held, then the information that we have favours Theism over either Atheism or Agnosticism. And, if we set aside all other information, except the information that the beliefs that God exists and that God does not exist are both held, then the information that we have does not favour either Theism or Atheism over Agnosticism. Big deal.

\section{MOTIVATIONALLY CENTRAL BELIEFS}

Pruss claims that if humanly excellent activity flows from some motivationally central belief, then, in the absence of any further information, we should say that the belief is more likely than not to be at least possible' (2010: 235).

While there are terms here that require further explanation, it should be noted at the outset that the discussion in the previous section suggests that Pruss is here underplaying his hand. Why not say this: if humanly excellent activity flows from some motivationally central belief, then, in the absence of any further information, we should say that the belief is more likely than not to be true? After all, unless 'motivationally central beliefs' are somehow more suspect than 'motivationally peripheral beliefs', the narrower claim is a simple consequence of the further observation that uniformly sampled beliefs are more likely than not to be true.

What are 'motivationally central beliefs'? Pruss writes:

I believe that I have a wife and kids. If I ceased to believe that, my life would change in widespread and significant ways, and many of the things that I am now motivated to do, I would no longer be motivated to do. My belief in the existence of my wife and kids, then, is one of the beliefs that are motivationally central to my life. (Pruss 2010: 234)

This passage suggests something like the following picture. A belief of mine is motivationally central just in case, were I to be rational, reflective, well-informed, and otherwise in good cognitive shape but lacking the belief in question, I would fail to have many of the motives for action 
that I now have. Many of my current actions are motivated by concern for my wife and kids; but, of course, I would not have that motivation if - despite being in good cognitive shape - I no longer believed that I have a wife and kids.

It is perhaps worth noting that talk about 'motivationallycentral beliefs' - understood in the way just outlined - need not involve commitment to an anti-Humean theory of motivation. Humeans deny that beliefs are motivational states: motivation is the exclusive provenance of desire, intention, and the like. But Humeans need not deny that beliefs and desires can rise and fall together: Humeans can allow that the having of certain beliefs is necessary for the having of given desires and intentions. However, there are other things that Pruss goes on to say - e.g. 'The most motivationally central beliefs are ones that actually rationally move us' (2010: 244) - which do suggest a commitment to an anti-Humean theory of motivation.

It is perhaps also worth noting that it is a further question whether the motivational centrality of beliefs is closely tied to centrality within one's web of beliefs. If we suppose that the relative centrality of a belief to one's web of beliefs is a matter of how much of one's web of beliefs would need to be revised in order for one to give up that belief (while remaining in good cognitive order), then it is not immediately obvious whether this kind of centrality coincides with motivational centrality. Consider, again, the case of the existence of my wife and kids. I take it that, were I to lack this belief while remaining in good cognitive order, this would be because I did not have a wife and kids. But, if that's right, then this case gives us no reason to deny that motivational centrality coincides with centrality in one's web of beliefs.

What is 'humanly excellent activity'? While he does not address this question directly, Pruss makes various indicative remarks. He says, for example, that humanly excellent activity requires 'a flourishing and intellectually sophisticated life for a significant period of time' (2010: 235); that a humanly excellent life would be 'an examined life' (2010: 235); that 'battling evil' is an important aspect of human flourishing (2010: 241); and that 'love for and friendship with others' is a central part of human flourishing (2010: 242). While this is hardly the place to argue these points, I would prefer a more pluralistic picture of human flourishing - cf. for example, Strawson (1974) and Wolf (1982) - and I would certainly resist the emphasis on 'intellectual sophistication' and 'the examined life'. I don't deny that the things that Pruss mentions can 
be part of humanly excellent activity; however, I am inclined to resist the suggestion that any of them is necessary for it.

What is it for action to 'flow from' a motivationally central belief? Given the account of 'motivationally central beliefs', one possible answer is that an action flows from a motivationally central belief just in case the action would not have been performed had the belief in question not been held. But this seems to have odd consequences. If I didn't have a wife and kids, I would not be living in the large house that I live in. But, if I weren't living in the house that I live in, I would not have gone to the fridge that I just went to in order to get the drink that I just consumed. So my getting the drink that I just consumed from the fridge in which it was located 'flowed from' my belief that I have a wife and kids? Given subsequent claims that Pruss wants to make about actions 'flowing from' motivationally central beliefs, I think that this cannot be what he has in mind.

Here's another suggestion. An action flows from a motivationally central belief just in case the best explanation of the action cites that belief (along with relevant desires, intentions, and so forth). On this account, we certainly avoid the previous problem: perhaps, for example, the best explanation of my going to the fridge cites only my thirst and my belief that there is water in the fridge that is mine to drink. However, while this manoeuvre may enable us to avoid commitment to the suggestion that my belief that I have a wife and kids is somehow instrumental in my going to the fridge to get a glass of water, it raises the prospects of a different kind of difficulty. For it is not clear that there are any 'humanly excellent' actions that I perform whose best explanation cites the fact that I believe that I have a wife and kids. (Of course, if asked, I will assent to the proposition 'I have a wife and kids'. Hence, some of my behaviour in filling out census forms and so forth is best explained in terms of this belief. But the actions in question don't seem to have much to do with 'human excellence. Of course, too, there are actions of mine that are candidates for 'humanly excellent' whose explanation adverts to beliefs that entail that I have a wife and kids: but it won't do to say that an action flows from a belief just in case the best explanation of the action either cites that belief, or else cites some other beliefs that entail that belief. Surely my filling out of census forms does not 'flow from' my belief that either I have a wife and kids or else I have some dirty washing that's been sitting in the back of my car for the past two weeks!)

Here is one last try. A belief that $\mathrm{p}$ entails a belief that q just in case p entails q. An action flows from a belief just in case the best explanation 
of the action adverts to that belief. A belief is motivationally central just in case many actions flow from beliefs that entail the belief in question. An action depends upon a belief just in case the action flows from a belief that entails the belief in question. Pruss' central claim is that, if humanly excellent activity depends upon a motivationally central belief, then, in the absence of any further information, we should say that the belief is more likely than not to be possibly true. Since I am not sure that this is what Pruss really has in mind, I shall stick with Pruss' original formulation for the remainder of my paper, and I shall simply ignore the worries just canvassed.

\section{TWO ARGUMENTS}

Pruss provides two arguments in support of the claim that, if humanly excellent activity flows from some motivationally central belief, then, in the absence of any further information, we should say that the belief is more likely than not to be at least possible.

First:

An impossible proposition entails all propositions. An intellectually sophisticated person or community reflects particularly on the entailments of beliefs that are motivationally central, and some of the motivational centrality is apt to transfer to the entailed claims. As a result, there is some likelihood that if a motivationally central proposition were in fact an impossible proposition, then the person or, especially, community would come up with an entailment $\mathrm{q}$ of the motivationally central proposition such that believing $\mathrm{q}$ would be damaging to flourishing. For instance, if they believed that circles are squares in a motivationally central way, they might draw the logical conclusion that pleasures are pains, and then they might torture people in order to give their victims pleasure. But to commit torture is significantly harmful to one's flourishing. (Pruss 2010: 235)

This is a strange argument. In the sense in which an impossible proposition 'entails' all propositions, it seems wrong to claim that an intellectually sophisticated person or community reflects particularly on the 'entailments' of beliefs that are motivationally central. Take my belief that I have a wife and kids. In the former sense of 'entails', this belief entails Fermat's Last Theorem. But there is no sense in which intellectually sophisticated persons and communities try to derive Fermat's Last Theorem from my belief that I have a wife and kids. (Of course, there 
actually are no persons and communities that have any interest at all in deriving consequences from the claim that I have a wife and kids - but the fact that people and communities lack this interest does not, I think, suffice to show that they lack intellectual sophistication!) I'm inclined to agree with O'Connor that we are 'committed to some "opaque" internal and external relations of necessity' (2008: 67). But, once we reject the imputed connection between 'necessity' and 'explicit formal logical contradiction', any prima facie plausibility in Pruss' argument simply evaporates.

It is perhaps also worth noticing that it is not very plausible to suppose that people do just blindly accept the consequences of applications of $e x$ falso quodlibet. As belief revisers, we are all well attuned to the 'garbage in, garbage out' principle. I am tempted to speculate that Pruss might here be conflating principles of logic with principles of rational belief revision (cf. Harman [1986]). Perhaps Pruss might say that there is surely some likelihood that even rational, reflective, well-informed inquirers might occasionally make this kind of egregious move - but I'm sceptical. Certainly, if I developed a derivation that pleasures are pains, I would be unshakeably certain that there was an error somewhere in that derivation; I would not be touting the derivation as proof of some hitherto undetected wisdom.

Second:

An important aspect of human flourishing involves humanly and morally and intellectually excellent activity flowing from motivationally central beliefs. Maybe it is possible that humanly excellent activity would flow from beliefs that are so far wrong as to be impossible, but it does not seem very likely. A humanly excellent life would be an examined life, and a part of the point of the examination is to ensure the compatibility of one's beliefs. (Pruss 2010: 235)

Plainly enough, this argument involves the same difficulties as the first argument. But it involves further difficulties as well. Even if we accepted that a humanly excellent life must be an examined life, it is not clear that part of the point of the examination is to ensure the logical consistency of one's beliefs. I think that we already have evolved strategies for coping with logical inconsistencies in our beliefs: in particular, there is a lot of modularity in our believing, and inconsistencies in our beliefs are harmlessly tolerated in consequence. Of course, when inconsistent beliefs arrive together at central processing, there is work to do: but, even then, we might preserve both beliefs in their quarantined or partitioned states (cf. Lewis [1982: 438]). 
Note that I am not here arguing for paraconsistency, or toleration of inconsistency in explicit theorising, or the like. I think that inconsistency is a fatal flaw in scientific and philosophical theories. But most of our believing is neither scientific nor philosophical. Moreover, many - perhaps most - of our 'motivationally central beliefs' are neither scientific nor philosophical. Consider, yet again, my belief that I have a wife and kids.

I conclude that Pruss's positive arguments for the claim that, if humanly excellent activity flows from some motivationally central belief, then, in the absence of any further information, we should say that the belief is more likely than not to be at least possible, are unconvincing. However, as noted above, I do not say that there is no other good way of arguing for this claim. In particular, I observe, again, that Pruss's claim is an easy inference from the claim that, if humanly excellent activity flows from some motivationally central belief, then, in the absence of any further information, we should say that the belief is more likely than not to be true.

\section{OBJECTION}

Pruss claims that 'a number of individuals and communities have led a flourishing and intellectually sophisticated life of significant length while holding a motivationally central belief that there is a maximally great being [God, a perfectly good, omnipotent, omniscient creator of all else who exists in all possible worlds]' (2010: 234). And from this - by way of the claim that, if humanly excellent activity flows from some motivationally central belief, then, in the absence of any further information, we should say that the belief is more likely than not to be at least possible - he concludes that, probably, it is possible that God exists.

More carefully, what Pruss concludes - or, at any rate, by his own lights, ought to conclude - is this: given just the information that there are a number of individuals and communities that have led flourishing and intellectually sophisticated lives of significant length while holding the motivationally central belief that God exists, and ignoring all other considerations, we should conclude that it is more likely than not that it is possible that God exists.

But, as we noted in our discussion of uniformly sampled beliefs and the likelihood of truth, in the context of the debate between Theists, Atheists and Agnostics, it is common ground that each position is widely held. Moreover, it seems indisputable that there are a number of individuals and 
communities that have led flourishing and intellectually sophisticated lives of significant length while holding motivationally central beliefs that entail that God does not exist. So oughtn't we also conclude that, ignoring all considerations other than the fact that there are a number of individuals and communities that have led flourishing and intellectually sophisticated lives of significant length while holding motivationally central beliefs that entail that God does not exist, it is more likely than not that it is possible that God does not exist (and perhaps even that it is much more likely than not that it is possible that God does not exist)?

Perhaps Pruss might be meaning to argue that, since there have been more individuals and communities that have led flourishing and intellectually sophisticated lives of significant length while holding the motivationally central belief that God exists than there have been individuals and communities that have led flourishing and intellectually sophisticated lives of significant length while holding motivationally central beliefs that entail that God does not exist, it is more likely than not that it is possible that God exists. But surely he's just wrong in thinking that belief in God (a perfectly good, omnipotent, omniscient creator of all else who exists in all possible worlds!) has been motivationally central in the majority of individuals and communities that have led flourishing and intellectually sophisticated lives of significant length. Consider the extent of flourishing and intellectual sophistication in lives of significant length in Ancient China, Ancient India, and Ancient Greece. Consider the extent of flourishing and intellectual sophistication in lives of significant length amongst Deists, Pantheists, Buddhists, and NonNecessitarian Theists (not to mention Free-Thinkers, Sceptics, Atheists, Rationalists, Naturalists, and Secularists of all stripes).

In response to this kind of objection, Pruss claims to have three moves available. For each case, he claims that he can argue (a) that the belief in question is actually compossible with the existence of God and so not in conflict with it; or (b) that the belief in question is either not motivationally central to a flourishing life or makes a less rational contribution to that life than theistic belief does to flourishing theists; or (c) that the belief in question is undercut by the existence of a decisive argument against it.

Given the conclusion that Pruss is aiming for, (c) seems to be beside the point. If we are ignoring all other considerations, then we are ignoring all other considerations. On his own account, Pruss is not claiming that 
the premise in his argument is an all-things-considered probability; rather, it is an all-other-things-ignored probability.

Given the conclusion that Pruss is aiming for, (a) seems to be of very limited use. On Pruss' own account, Theism says that every possible world contains an omnipotent, omniscient, perfectly good creator of everything else. Any view that holds that it is possible that there is not an omnipotent, omniscient, perfectly good creator of everything else is not 'compossible' with Theism. Likewise for any view that holds that it is actually the case that there is not an omnipotent, omniscient, perfectly good creator of everything else. Almost all non-Theistic worldviews fit into both of these categories.

Given the conclusion that Pruss is aiming for, deployment of (b) also seems to have very limited use. What Pruss wants to argue is that, whereas the belief that God exists is motivationally central for (many) Theists, the beliefs that entail that God does not exist are not motivationally central for (many) non-Theists. But, no matter how we understand 'motivational centrality', this seems broadly implausible. It is evidently true that the actions and motives of many non-theists would be vastly different if they gave up those of their beliefs that entail that God does not exist (while remaining in good cognitive shape). It is no less plainly true that relevant counterparts to the belief that God exists - e.g. the belief that causal reality is exhausted by natural reality - figure equally prominently in explanations of particular actions. (Why did I squirm when my sole Theistic guest insisted on loudly saying grace before dinner? Why did I spend almost every waking minute of last weekend playing cricket? Why did I insist that my children be excused from religious indoctrination sessions at school? Etc.) Of course, to claim 'equal prominence' is not necessarily to claim that any such beliefs do figure prominently in explanations of particular actions: we have already noted grounds for scepticism about how much of my behaviour is actually explained in terms of my belief that I have a wife and kids (and similar grounds could be urged in connection with the belief that God exists and the belief that causal reality is exhausted by natural reality). However, even if equal prominence is only equal lack of prominence, that would suffice to defeat Pruss' view.

Perhaps there is something further that Pruss might say in response to these objections to deployment of (b). He says the following things: 
Belief in God typically enters motivationally into the lives of persons and communities in multiple ways. It makes them see the natural world around them as created by God, and it makes it possible for them to see their neighbour as made in the image of God. It gives them hope in a providential government of the world. It confers a deep felt meaning on their lives and the lives of those around them, by entailing that somehow behind this physical reality there is that than which no greater can be thought. It gives fruit for meditation and grounds contemplation, which not only are constitutive parts of a person's flourishing, but profoundly help form distinctive character traits. Divine love provides an example for meditation. And so on. (Pruss 2010: 236)

While it seems likely that theism tends to be central to the motivational life of theists, to many atheists atheism is not motivationally central. The atheist probably does not kiss her husband because she thinks that there is no God, and it is arguably unlikely that she helps the needy because she thinks there is no God. But a theist might well kiss her husband because she believes that the spousal relationship is a reflection of God's love, and she might help the needy because the needy are children of God. In fact, it seems that there is something crabbed in a life motivationally centred on a negative doctrine like atheism. (Pruss 2010: 243)

The most central of beliefs are going to motivate not just one's scientific life, but also one's interpersonal life. And there the belief that all causation is natural causation does not seem helpful. It might even induce worries about free will and responsibility that are deleterious to flourishing. The theistic scientist, on the other hand, can be motivated in both her interpersonal life by her seeing others as images of God as well as in her scientific life by a belief that God exists and would likely give created agents epistemic powers at least somewhat commensurate with their thirst for knowledge. (Pruss 2010: 245)

I take it that what Pruss is effectively saying here (and in related passages sprinkled throughout his article) is that those who believe that God exists - while leading flourishing and intellectually sophisticated lives of significant length - typically exhibit certain kinds of virtues because they hold the belief that God exists, whereas those who do not believe that God exists - while leading flourishing and intellectually sophisticated lives of significant length - exhibit the virtues that they do in fact exhibit in spite of the beliefs that they hold that entail that God 
does not exist. If this is what Pruss is saying, then it seems to me that what he says is largely the expression of theistic prejudice.

If we accept what Pruss says about what belief in God can do, then we can hardly deny that belief in God can also: make it possible for people to see their neighbours as competitors for, or obstacles to, their own salvation; give people overwhelming fear of eternal punishment and damnation; destroy meaning and value by orienting believers lives around merely hoped for future existence (if, indeed, God does not actually exist); and so forth. Moreover, if we look at data that seems relevant to human flourishing - e.g. correlations between religiosity and societal dysfunction - we find that, if anything, there is a correlation between diminished religiosity and improved societal outcomes (see Paul [2005]). At the very least, this data certainly does not speak in favour of the motivational superiority of belief in God. Consequently, it seems to me to be incredible to suppose that there is the sharp division that Pruss discerns, within the class of those who lead flourishing and intellectually sophisticated lives of significant length, between those who hold worldviews that entail that God exists and those who hold worldviews that entail that God does not exist. As far as I can see, flourishing falls equally upon those who have God-entailing worldviews and those who have God-denying worldviews. Moreover, as far as I can see, the belief that God exists has no greater role in explaining the flourishing of those who have God-entailing worldviews than beliefs that entail that God does not exist have in explaining the flourishing of those with God-denying worldviews. It is implausible to suppose that worldviews have some extra motivational role for believers that they do not have for non-believers; it is no less implausible to suppose that the belief that God exists is somehow more central to God-entailing worldviews than claims that entail that God does not exist are to God-denying worldviews.

Perhaps it is worth noting here that I agree with Pruss that an atheist does not kiss her husband because she thinks that there is no God, and nor does she help the needy because there is no God. Rather, an atheist kisses her husband because she loves him, and helps the needy because they are in need of help. If a theist kisses her husband because she believes that the spousal relationship is a reflection of God's love, and helps the needy because the needy are children of God, then - pace Pruss - it seems to me that it is the theist who has the crabbed motivation. At the very least, it seems that her husband can justly complain that there is one thought too many involved in that kiss; and the needy could justly 
complain that there is one thought too many involved in that charitable activity (cf. Williams [1981: 18]).

Perhaps it is also worth noting that Pruss' claims about the ways in which belief in God can enter motivationally into the lives of people and communities do not ring entirely true. What Pruss is trying to establish is that the belief that God exists enters motivationally into the lives of people and communities. But it is sleight of hand to transfer motivational consequences from belief in God to the belief that God exists. After all, one could believe that God exists without believing that one's neighbours are made in the image of God, or that there is an afterlife, etc. To say that someone believes in God is typically to say - or perhaps implicate - that that one has certain kinds of motivations (though no doubt there is a role for context, interest, and so forth in the determination of the relevant class of motivations); to say that someone believes that God exists is typically not to say - or perhaps implicate - anything much about that person's motivations.

Perhaps it is further worth saying that the belief that all causation is natural causation -i.e. that there are no supernatural causes or supernatural agents - plainly has some beneficial motivational consequences: after all, pretty much everyone agrees that most beliefs about supernatural causes and supernatural agents are false, and that most superstitious beliefs militate against human flourishing. Moreover, it is unclear why it is impossible to maintain that natural causation includes natural agent causation - and so it is unclear why the belief that all causation is natural causation should be thought to be a potential threat to moral responsibility even by those who suppose that agent causation is necessary for moral responsibility.

I conclude that Pruss has certainly not made good his claim that beliefs that entail that God does not exist are either not motivationally central to flourishing lives or else makes less rational contributions to those lives than theistic beliefs do to the lives of flourishing theists.

More broadly, I conclude that there are many different reasons for being sceptical about Pruss' (implicit) assertion that considerations, about the motivational role that the belief that God exists plays in Godentailing worldviews and the motivational role that beliefs that entail that God does not exist play in God-denying worldviews, significantly support the contention that relative only to information about flourishing and intellectually sophisticated lives of significant length, the possibility of God's existence is more likely than not. 


\section{FURTHER CONSIDERATIONS}

Pruss' paper raises a number of other interesting considerations. I have space to comment upon only a few of them.

First, it is worth noting that there is a genuine dispute about the connection between false belief and human flourishing. Pruss allows that it might be that false beliefs are central to flourishing human lives:

One can imagine a doctor who leads a flourishing and intellectually sophisticated life bringing an expensive cancer treatment to the needy. A belief in the effectiveness of the treatment will be motivationally central to her life, but her life is not much less a flourishing human life should it turn out that all the studies that claimed the treatment to be effective were in fact wrong. (Pruss 2010: 234)

It is not obvious that Pruss is right about this case. A natural judgment in this case is that the doctor wasted her life: she did no better than she would have done had she organised large shipments of sugar pills to those with cancer. More generally, one might think - as I believe that Aristotle did - that having true motivationally central beliefs is a necessary condition for human flourishing. However, if getting things right - or, at any rate, not getting things wrong, at least in certain ways - is necessary for flourishing, then there is a clear potential threat to Pruss' argument. If, for example, Theistic belief is consistent with flourishing just in case Theistic belief is true, then it becomes impossible to assess the truth of Pruss' key premise without a prior assessment of the comparative merits of Theism, Atheism and Agnosticism. (And, of course, there are many Theists who do suppose that their flourishing depends upon the truth of their Theistic beliefs: 'If Christ be not risen, my life is all in vain', etc.)

Second, it is worth observing that Pruss makes quite a deal about the possibility of motivationally central beliefs in flourishing and intellectually sophisticated subjects that involve 'Kripkean' necessary falsehoods:

(i) George believes that Dorothy is his biological daughter and this belief is near the motivational centre of his life, but Dorothy is not his daughter, having been swapped at birth. (ii) Patricia believes that electrons are manifestations of a field, and her life-work as a physicist is centred on this belief, but in fact electrons are essentially particles. (iii) A fair amount of Dr. Livingstone's activity was based on the assumption that the Lualaba River was the Nile; but, in fact, the Lualaba was the Upper Congo, and so it is metaphysically impossible that the Lualaba be the Nile. (Pruss 2010: 237) 
Pruss essays two responses to these kinds of cases. The 'more daring' response is to insist that 'motivational centrality of these kinds of beliefs detracts from the flourishingness of lives' (2010: 237):

George would flourish more if he focussed less on the biological aspects of paternity. Patricia would live a more intellectually open scientific life if she were more open to the possibility of field theories of electrons being false. And Dr. Livingstone would perhaps have done more good to the science of geography were he not focussed on a Quixotic quest for the sources of the Nile. (Pruss 2010: 237)

To the extent that these responses push in the direction of the idea that flourishing depends upon not holding false beliefs - or at least not holding certain kinds of false beliefs - these responses also raise the possibility that it is not possible to assess the truth of Pruss' key premise without a prior assessment of the comparative merits of Theism, Atheism and Agnosticism.

Pruss favours - 'presses' - a response that invokes two-dimensionalism. If we say that a sentence $S$ is metaphysically possible just in case its secondary intension is true at some world, and conceivable just in case its primary intension is true at some world, then we can accommodate 'Kripkean' cases by modifying the central claim in Pruss' argument so that it says that: 'if humanly excellent activity flows from some motivationally central belief, then, in the absence of any further information, we should say that the belief is more likely than not to be at least possible or conceivable. However - as Pruss in effect notes, at least inter alia even if we have no qualms about the two-dimensional framework, it is obvious that this framework is insufficient to represent the dispute between Theists, Atheists and Agnostics. A 'neutral' - or 'negotiated' representation of the concept of God will have it that either (as Theists suppose) God exists in all possible worlds, or else (as Atheists suppose) God exists in no possible worlds. Given that we hold fixed the identity of primary and secondary intension in the case of 'God', there are still two 'possibilities' for the relevant 'unified' intension of 'God' (all worlds, or none). Of course, these 'possibilities' are not jointly representable in the two-dimensional framework as either metaphysically possible or conceivable - but the correct conclusion to draw from this, I think, is that accommodation of 'Kripkean' cases is a peripheral concern that has no bearing on the main game (given that our interest lies in addressing questions about the existence of God). 
Third, it is worth paying some further attention to Pruss' claim that the probability of the possibility of motivationally central beliefs:

... increases roughly in proportion to such factors as: how motivationally central the belief is, how flourishing the individual or community $\mathrm{x}$ is, how much of x's humanly excellent activity flows from that belief, how rational the motivational connection between the belief and the humanly excellent activity is, how intellectually sophisticated $\mathrm{x}$ is, how long the time span involved is, how large a community $\mathrm{x}$ is, and so on' (Pruss 2010: 236).

Perhaps there is a sense in which this is at least partly right. In the absence of all other information, perhaps we should judge that beliefs that everybody holds are more likely to be true than beliefs that only some people hold. In the absence of all other information, perhaps we should judge that majority beliefs - beliefs that are held by the majority of people - are more likely to be true than beliefs that are only held by a minority of people.

However, once we add in the information that there is serious protracted, perennial - disagreement about a claim, it becomes much less clear that we should suppose that majority opinion is more likely to be correct. As noted above, the context within which Pruss' argument is constructed is one in which it is taken for granted that there is serious protracted, perennial - dispute between Theists, Atheists, and Agnostics. In the context of assessment of Pruss' argument, there is something very odd about the suggestion that the information that there is serious protracted, perennial - disagreement about the existence of God might be properly ignored, or that serious interest attaches to questions about what one ought to think if this information is part of the information that is ignored.

Fourth, Pruss has remarks to make about polytheism, pantheism, illusionism, and non-religious atheism that work with the strategies (a)-(c) that he suggests can be used to defeat the claim that there have been significant numbers of individuals and communities that have led flourishing and intellectually sophisticated lives of significant length while holding motivationally central beliefs that entail that God does not exist. Many of these remarks seem to me to misrepresent the views in question.

Consider polytheism. I take it that polytheists believe that there are many gods: many supernatural beings or forces that have and exercise power over natural reality that are not, in turn, under the power of higher-ranking or more powerful beings or forces. But, if there are many gods, and if there is nothing that has and exercises power over any 
of the gods, then there is no maximally great being. But then, pace Pruss, polytheism entails the denial of Theism, and nothing that he says tells against the idea that there have been individuals and communities that have led flourishing and intellectually sophisticated lives of significant length while holding motivationally central polytheistic beliefs.

Consider pantheists. I take it that pantheists deny that it is possible that deity exist even though the physical universe does not; whereas, on Pruss' own account, Theists allow that it is possible that God exists, even though the physical universe does not (because, say, God chooses not to create anything else). But then, pace Pruss, deity is necessarily distinct from God, and pantheism entails the denial of Theism. Again, nothing that Pruss says tells against the idea that there have been individuals and communities that have led flourishing and intellectually sophisticated lives of significant length while holding motivationally central pantheistic beliefs.

Etc. (I leave examination of Pruss' other cases to the interested reader.) One final observation that is perhaps worth making is that Pruss does not have anything to say about the case of theists who are not Theists, i.e. about those who think that there is just one god, but that this god is not 'essentially omnipotent, essentially omniscient, essentially perfectly good, essentially the creator of all else, and necessarily existent. His argument requires that individuals and communities who hold motivationally central beliefs that are theistic but non-Theistic are less likely to lead flourishing and intellectually sophisticated lives of significant length than individuals and communities who hold motivationally central beliefs that are Theistic. I do not think that I will be alone in finding this somewhat implausible: at the very least, I'd like to know what reason there could possibly be to accept this.

\section{CONCLUDING REMARKS}

Pruss claims that the following argument 'provides [defeasible] reason to believe that there exists a being that is perfectly good, omnipotent, and omniscient in all worlds' (2010: 248):

(1) Necessarily, if $\mathrm{x}$ is a maximally great being, then $\mathrm{x}$ exists in all possible worlds and is perfectly good, omnipotent, omniscient, and creator of any and all contingent beings in every world.

(2) If $\mathrm{x}$ is a human individual or community that leads a flourishing and intellectually sophisticated life of significant length while holding a motivationally central belief that $\mathrm{p}$, then, probably, it is possible that $\mathrm{p}$ is true. 
(3) A number of individuals and communities have led flourishing and intellectually sophisticated lives of significant length while holding a motivationally central belief that there is a maximally great being.

(4) (Therefore) Probably it is possible that there is a maximally great being. (From 2, 3)

(5) (Therefore) Probably there is a maximally great being. (From 1,4) However, the merits of Pruss' argument come most clearly into view when we compare it with the following argument:

(1) Necessarily, if $\mathrm{x}$ is a maximally great being, then $\mathrm{x}$ exists in all possible worlds and is perfectly good, omnipotent, omniscient, and creator of any and all contingent beings in every world.

(2) If $\mathrm{x}$ is a human individual or community that leads a flourishing and intellectually sophisticated life of significant length while holding motivationally central beliefs that entail that $p$, then, probably, it is possible that $\mathrm{p}$ is true.

(3) A number of individuals and communities have led flourishing and intellectually sophisticated lives of significant length while holding motivationally central beliefs that entail that there is no maximally great being.

(4) (Therefore) Probably it is possible that there is no maximally great being. (From 2, 3)

(5) (Therefore) Probably there is no maximally great being. (From 1, 4) There are two significant options. On the one hand, Pruss could concede that the latter argument provides defeasible reason to believe that there does not exist a being that is perfectly good, omnipotent, and omniscient in all worlds. However, if we take this path, then it seems clear that the defeasible reasons annul one another: taken together, the two arguments do nothing to resolve the dispute between Theists, Atheists and Agnostics. (And this is true whether or not we remember to interpret the 'probability' in question as an 'all-other-things-ignored' probability.) On the other hand, Pruss could insist that, while the third premise in the first argument is true, the third premise in the second argument is false. But it seems to me that there is no construal of the key terms that are used in the formulation of these third premises under which rational Agnostics and Atheists are obliged to concur. Indeed, I think that only Theistic prejudice against Atheists - including theists! - and Agnostics could lead one to suppose that there is neutral reason to give greater 
credence to the third premise of the first argument than to the third premise of the second argument.

One final observation. There is a question to ask about the connection between worldviews and human flourishing. Whether individuals and communities lead flourishing and intellectually sophisticated lives may be dependent upon worldview. If so, then worldviews are motivationally central, and the facts about the distribution of individual and community flourishing suggest that, among worldviews, Theistic worldviews can claim no special motivational privilege. On the other hand, if not, then worldviews are not motivationally central, and, ipso facto, Theistic worldviews can claim no special motivational privilege. Either way, then, Theistic worldviews can claim no special motivational privilege. Perhaps - perhaps! - if worldviews are motivationally central, the belief that God exists has a particular motivational centrality in Theistic worldviews that is not matched by any corresponding single belief in non-Theistic worldviews. But, even if so, this supplies no one with reason to suppose that the belief that God exists is possibly true. Or so it seems to me.

\section{BIBLIOGRAPHY}

Harman, G. 1986. Change in View (Cambridge: MIT Press)

Lewis, D. 1982. 'Logic for Equivocators', Noûs, 16: 431-41

O'Connor, T. 2008. Theism and Ultimate Explanation (Oxford: Blackwell)

Paul, G. 2005. 'Cross-National Correlations of Quantifiable Societal Health with Popular Religiosity and Secularisms in Prosperous Democracies', Journal of Religion and Society, 7: 1-17

Pruss, A. 2010. 'The Ontological Argument and the Motivational Centres of Lives', Religious Studies, 46: 233-49

Strawson, P. 1974. 'Social Morality and Individual Ideal' in his Freedom and Resentment, and Other Essays (London: Methuen), pp. 26-44

Williams, B. 1981. 'Persons, Character and Morality' in his Moral Luck (Cambridge: Cambridge University Press), pp. 1-19

Wolf, S. 1982. 'Moral Saints', Journal of Philosophy, 79: 419-39 